\title{
TRAMA DE 'FLORESCERES' NO ENSINO DA CIÊNCIA. PERCURSOS ORIENTADOS POR ENTRELAÇOS DE AMOROSIDADE, CONFIANÇA E ALEGRIA, EM PROCESSOS AUTOPOIÉTICOS DE ENSINO E PRODUÇÃO DA CIÊNCIA
}

\author{
TRAMA DE 'FLORECERES' EN LA ENSEÑANZA DE LA CIENCIA. CAMINOS \\ ORIENTADOS POR ENTRELAZOS DE AMOROSIDAD, CONFIANZA Y ALEGRÍA EN \\ PROCESSOS AUTOPOIÉTICOS DE ENSEÑANZA Y PRODUCCIÓN DE LA CIENCIA
}

\author{
WEFT OF 'FLORESCERES' ON SCIENCE TEACHING. ROUTES GUIDED BY \\ INTERLACE OF AMOROUSNESS, TRUST AND JOY, IN AUTOPOIETIC PROCESSES \\ OF TEACHING AND PRODUCTION OF SCIENCE
}

Maria Luiza Cardinale BAPTISTA ${ }^{1}$

RESUMO: O texto tem caráter ensaístico, como resultado de 30 anos de docência, pesquisa e consultoria e supervisão de textos, ligados à produção da Ciência, em diversas áreas. Trama de 'floresceres', no ensino da Ciência, propõe apresentar sinalizadores encontrados nos percursos de ensino, orientados pelos pressupostos de amorosidade, confiança e alegria, em processos autopoiéticos, envolvendo estudantes de graduação, especialização, mestrado e doutorado em várias áreas, especial e diretamente, no trabalho desenvolvido em seis universidades brasileiras, com parcerias com pesquisadores de, pelo menos, oito países. $\mathrm{O}$ referencial teórico é transdisciplinar, marcado fortemente pela Esquizoanálise de Félix Guattari e Gilles Deleuze, bem como por pressupostos epistemológicos de mutação da Ciência Contemporânea, sinalizados por autores como Fritjof Capra, Roberto Crema, Boaventura de Souza Santos, Deepak Chopra, Amit Goswmani, Marcelo Gleiser, entre outros. Em Educação, destaca-se o pensamento de Paulo Freire, Francisco Varela e Humberto Maturana, sempre em associação aos pressupostos esquizoanalíticos, especialmente referente às máquinas autopoiéticas de produção de subjetividade. Em termos metodológicos, o texto tem orientação da estratégia autoral denominada Cartografia dos Saberes, em combinação com as Matrizes Rizomáticas, buscando a combinação entre as quatro trilhas de investigação: Saberes Pessoais, Saberes Teóricos, Usina de Produção e Dimensão Intuitiva da Pesquisa, com o alinhamento matricial dos fluxos narrativos, possíveis de serem apreendidos apenas em rizomas reflexivos.

PALAVRAS-CHAVE: Ciência. Ensino. Cartografia dos saberes. Matrizes rizomáticas. Amorcomtur. Amorosidade.

\footnotetext{
${ }^{1}$ Universidade de Caxias do Sul (UCS), Caxias do Sul - RS - Brasil. Professora e Pesquisadora do Programa de Pós-Graduação em Turismo e Hospitalidade e dos cursos de Comunicação Social da UCS. Coordenadora do Amorcomtur! Grupo de Estudos em Comunicação, Turismo, Amorosidade e Autopoiese. Professora Colaboradora da Universidade Federal do Amazonas (UFAM). Pós-doutoranda em Sociedade e Cultura da Amazônia (UFAM). Doutora em Ciências da Comunicação pela ECA/USP. ORCID: http://orcid.org/0000-00027096-1160. E-mail: malu@pazza.com.br
} 
RESUMEN: El texto tiene carácter ensayístico, como resultado de 30 años de docencia, investigación y consultoría y supervisión de textos, relacionados a la producción de la Ciencia, en diversas áreas. Trama de 'floreceres', en la enseñanza de la Ciencia, propone presentar señalizadores encontrados en los caminos para la enseñanza, orientados por los supuestos de amorisidad, confianza y alegría, en procesos autopoiéticos, involucrando estudiantes de grado, especialización, maestría y doctorado en varias áreas, especial y directamente, en el trabajo desarrollado en seis universidades brasileñas, en colaboración con investigadores de por lo menos ocho países. El referencial teórico es trasdisciplinar, marcado fuertemente por la Esquizoanalisis de Félix Guattari y Gilles Deleuze, así como por supuestos epistemológicos de mutación de la Ciencia Contemporánea, señalados por autores como Fritjof Capra, Marcelo Gleiser, entre otros. En Educación, se destaca el pensamiento de Paulo Freire, Francisco Varela y Humberto Maturana, siempre en asociación a los supuestos esquizoanaliticos, especialmente referente a las máquinas autopoiéticas de producción de subjetividad. En términos metodológicos, el texto tiene orientación de la estrategia autoral nombrada Cartografía de los Saberes, en combinación con las Matrices Rizomáticas, buscando la combinación entre las cuatro trillas de investigación: Saberes Personales, Saberes Teóricos, Usina de Producción y Dimensión Intuitiva de la Investigación, con el alineamiento matriarcal de los flujos narrativos, posibles de ser aprehendidos solo en rizomas reflexivos.

PALABRAS CLAVE: Ciencia. Enseñanza. Cartografía de los Saberes. Matrices Rizomáticas. Amorcomtur. Amorosidad.

ABSTRACT: The text has an essayistic character, as a result of 30 years of teaching, research, consulting and supervision of texts, linked to the science production, in several areas. The weft of 'floresceres', on Science teaching, proposes to present signs found in the teaching pathways, guided by assumptions of amorousness, trust and joy, on autopoietic process, involving graduating students, specialization, master's degree and doctorate degree in many areas, special and directly, in the work developed on six brazilian universities, with partnerships with researchers of, at leats, eight countries. The theoretical referential is transdisciplinary, Strongly marked by Schizoanalysis of Félix Guattari and Gilles Deleuze, as well as by epistemological assumptions of contemporary science mutation, signaled by authors as Fritjof Capra, Roberto Crema, Boaventura de Souza Santos, Deepak Chopra, Amit Goswmani, Marcelo Gleiser and others. On education, stands out the thouth of Paulo Freire, Francisco Varela and Humberto Maturana, always in association to the schizoanalytical assumptions, especially regarding the autopoietic machines of subjectivity production. In methodological terms, the text has a guiding of authoral strategy named as Knowledge Cartography, in combination with Rhizomatic Matrices, seeking the combination between four investigation paths: Personal Knowledge, Theorical Knowledge, Factory Production and Intuitive Dimension of the Research, with the matrix alignment of narrative flows, with the matrix alignment of narrative flows, possible to be apprehended only in reflective rhizomes.

KEYWORDS: Science. Teaching. Knowledge Cartography. Rhizomatic Matrices. Amorcomtur. Amorousness. 


\section{Primeiros entrelaços da trama}

Este texto decorre da intenção de compartilhar reflexões, decorrentes de processos vividos em interações com pesquisadores em percursos de aprendizagem e investigativos, em vários níveis. Pelas características esquizoanalíticas e caosmóticas do meu trabalho, nesses 30 anos de docência, o que tenho para escrever é resultado desses processos, numa mescla de reflexões epistemológico-teóricas e relato de experiência Amorcomtur!, Grupo de Estudos em Comunicação, Turismo, Amorosidade e Autopoiese, da Universidade de Caxias do Sul, com a proposição da estratégia metodológica Cartografia dos Saberes e Matrizes Rizomáticas, para o ensino da pesquisa. A proposição 'trama de floresceres' associada à Educação tem inspiração em trabalho desenvolvido na Universidade Federal do Amazonas, como pesquisadora visitante sênior, professora colaboradora do Programa de Pós-Graduação em Ciências da Comunicação, Professora colaborada do Programa de Pós-Graduação em Sociedade e Cultura da Amazônia, pós-doutoranda em Sociedade e Cultura da Amazônia, palestrante em diversas ocasiões, consultora em projetos da Pró-Reitoria da Pesquisa e Pós-Graduação, voltados à discussão de amorosidade, com reuniões realizadas com gestores de todas as áreas da instituição. Nesse tempo em interação com a Amazônia, compreendi saberes da floresta, de floresceres, que já haviam em mim, no sentimento, em potência de ser floresta, capaz de sobreviver às intempéries e ser obstinada em florações, em todo canto, todos os dias.

Ao longo desses 30 anos de vivências, reflexões e estudos sobre o ensino da pesquisa, foi possível perceber que o entrelaçamento dos pressupostos amorosidade, confiança e alegria é decisivo para a produção da Ciência, que signifique autopoiese para o sujeito que pesquisa e o campo investigado. Nesse sentido, a metáfora da floresta e dos floresceres ajuda a compreender que a Ciência precisa ser semeada, nutrida, tem tempo de amadurecimento e brotação e só floresce com a potência de vida acionada. Para tanto, amorosidade, como ética do cuidado, combinada com a confiança em si e no outro mostram-se como aspectos cruciais, sem os quais nenhuma engrenagem maquínica, nenhum aparato tecnológico ou sofisticado laboratório fará brotar conhecimento.

A Floresta, como pressuposto epistemológico e metáfora existencial e teórica, é uma das minhas grandes marcas e orientações. Floresta é trama e processo, constante acionamento de processo. Melhor seria dizer que floresta, nesse sentido, é sempre verbo, florescer. Por isso, é importante, neste texto, embrenhar-se nos meandros do processo de constituição dessa floresta, ou dessa trama de floresceres, a que me refiro. 
A estratégia metodológica para a produção do texto e das minhas investigações como ações de investimentos em determinadas direções - é a Cartografia dos Saberes. Criei essa estratégia com o intuito inicial de ajudar pesquisadores iniciantes que, muito frequentemente, se sentem perdidos e não sabem por onde, nem como começar. Aos poucos, fui me dando conta que todos nós, independentemente do estágio de amadurecimento científico em que estamos, em determinados momentos, nos sentimos perdidos e, mais que isso, entendi que não se trata de um problema ou uma deficiência ou falta de capacidade do pesquisador. Ao contrário, tenho dito que, na pesquisa e na vida, perder-se também é caminho, principalmente caminho para novas descobertas, para o agenciamento de novos percursos, com mais criatividade e com o acionamento mais intenso da potência de vida. Tentando voltar para o suposto caminho, nós agenciamos linhas de fuga (no sentido esquizoanalítico, caminhos vicinais que se escampam das linhas duras - viciadas) e produzimos estrada nova, geralmente com florescimentos vários.

Em síntese, a Cartografia dos Saberes é uma estratégia de abordagem do fenômeno estudado, que se orienta por quatro grandes trilhas principais, agenciadas simultaneamente e que vão se entrelaçando: Saberes Pessoais, Saberes Teóricos, Usina de Produção e Dimensão Intuitiva da Pesquisa. O agenciamento da produção da Cartografia é feito com a compreensão de que se trata de uma espécie de mapeamento mutante, produzido com aproximações e ações investigativas. Suely Rolnik (1989), uma das autoras que inspiram essa proposição, apresenta no seu livro Cartografia Sentimental, o Manual do Cartógrafo, com base metodológica sensível para a produção de sua pesquisa sobre a subjetividade feminina. Neste texto, ela afirma que a cartografia é uma espécie de mapa que se faz acompanhando as mudanças da paisagem. Assim. Podemos pensar que, quando vamos fazer uma pesquisa, precisamos começar mapeando os recursos que temos, o que já sabemos, o que pretendemos, o que sentimos em relação ao objeto de estudo, mas, ao pensar nisso, podemos lembrar que mapa é a delimitação de um território fíxo, estabelece os limites e lhes dá visualidade, enquanto a cartografia, como conceito da Geografia, é escrita a partir das mudanças das cartas geográficas, já tem, em si, o caráter processual, no sentido de compreender as mutações, as transformações entre uma 'carta geográfica', um mapa e outro.

Suely Rolnik trouxe o conceito para processos psicossociais, eu o tenho associado a muitos fenômenos e processos de áreas diversas, na perspectiva transdisciplinar em que venho trabalhando, como docente de pesquisa nas áreas da Comunicação, Turismo, Educação, Psicologia, Sociedade e Cultura da Amazônia, Serviço Social, Medicina, nas seguintes universidades brasileiras: Universidade de Taubaté (Taubaté/SP), Universidade Luterana do 
Brasil (Canoas/RS), Universidade do Vale do Rio dos Sinos (São Leopoldo/RS), Universidade Federal do Rio Grande do Sul (Porto Alegre/RS), Universidade Federal do Amazonas (Manaus/AM) e Universidade de Caxias do Sul (Caxias do Sul/RS), diretamente, sem contar trabalhos esporádicos com palestras, oficinas, painéis, cursos de extensão, em tantas outras. Também venho aplicando a Cartografia dos Saberes, na supervisão de textos de pesquisa de profissionais em praticamente todas as áreas do Conhecimento, da Filosofia à Matemática, passando por Medicina, Agronegócio, Geografia, Urbanismo, Serviço Social, História, Educação, Psicologia, Comunicação, Turismo, Marketing, Administração, Direito, Engenharia, Secretariado Executivo, entre outros, em trabalho técnico profissional que realizo na empresa Pazza Comunicazione, de Porto Alegre.

Em coerência com a Cartografia dos Saberes, a estratégia narrativa deste texto segue as trilhas indicadas, oferecendo ao leitor sinalizadores dos percursos, desde o percurso pessoal da pesquisadora-autora, passando pelo encontro com os saberes dos outros, na Trilha de Saberes Teóricos, seguido da Trilha Usina de Produção, com relato de alguns processos da história do Amorcomtur, todos perpassados pela Trilha da Dimensão Intuitiva da Pesquisa, a expressão da potência de fluxos invisíveis, indizíveis, intensos e potencializadores da produção da Ciência e das relações de ensino-aprendizagem.

\section{Trama de floresceres - Saberes Pessoais}

Num primeiro momento, pode parecer estranho que uma cientista fale de sua produção e do ensino de seu ofício, usando a expressão 'trama de floresceres'. Para algumas pessoas, desavisadas, isso pode soar pueril, ingênuo. Alerto: não é uma expressão usada ao acaso, sem reflexão, sem convicção profunda. Não é uma expressão qualquer, usada apenas pela poética de sua construção. Ao contrário, é usada pela poética da sua construção, mas não 'apenas', e sim, 'sobretudo' pela potência poética de sua construção - poiese, produção, potência acionada de florescimentos vários. Sua construção, como pressuposto epistemológico-teórico, vem de longa data, na inscrição na vida de uma criança, que cresceu no interior de São Paulo 'fazendo flores', em uma fábrica de flores familiar, que se instalou em uma pequena cidade, no antigo prédio do único cinema local, que tinha fechado. A fábrica envolvia o trabalho direto de mais de 40 famílias, na produção de folhas e flores, dos mais diferentes tipos, de tecidos, que depois eram reunidas em ramalhetes, arranjos, encaixotadas e encaminhadas para várias partes do país e do mundo. Era a Fábrica de Flores Santa Rita, no município de Guarantã, São Paulo, de propriedade da família dessa que, anos mais tarde, seria escritora, 
jornalista, pesquisadora, professora, cientista, empenhada e fazer florescer mais e mais estudantes apaixonados pela produção do conhecimento, da Ciência.

A ideia de produção de flores artificiais para vender surgiu de um sonho de minha mãe, com meu nonno (avô, em italiano), que já tinha morrido há muito tempo. Da lembrança desse sonho, houve o início da produção e desencadeou-se um processo de florescimento da atividade na família, que, depois, se expandiu por muitas outras famílias e foi responsável pelo sustento de muita gente. O sinalizador aqui é a dimensão intuitiva ${ }^{2}$, capaz de nos ajudar a resolver problemas, na pesquisa e na vida. Há sinalizadores invisíveis, que brotam de níveis subconscientes, quando estamos diante de problemas existenciais e investigativos. $\mathrm{O}$ fato de nos dedicarmos de nos implicarmos com a situação intensa e afetivamente faz com que o universo a nossa volta se movimente em torno de soluções. Assim, é muito comum que elas, as soluções, brotem de fragmentos do cotidiano, de lugares inesperados, às vezes quando dormimos ou estamos, aparentemente, desconectados com o núcleo do problema. Seguir o sonho também é uma metáfora, ao mesmo tempo que uma voz de comando para a prática de floresceres na Ciência. Tem sido assim, para mim, também na pesquisa e nas práticas do ensino dos florescimentos na Ciência. O Cientista é um sujeito que sonha e faz!

Manhã de sol na pequena Guarantã, interior de São Paulo, região de Bauru. As portas laterais do antigo prédio do cinema se abriam e começavam a chegar os funcionários, para retomar seus lugares na produção de flores. Uns iam para as prensas e logo ligavam o fogo, para começar a prensar as pétalas, que dali saiam com frisos marcados, que dariam as belezas da flor, mais tarde, na composição do arranjo. Outros faziam os miolos, ou colavam as folhas nos cabinhos que iriam permitir que elas fossem juntadas aos arranjos de flores. Alguns colavam as flores nos miolos e as penduravam em varais. Aos poucos, os varais iam se enchendo, vasos iam ficando também plenos de galhos produzidos cuidadosamente com a junção de flores, flores e brotos. O ambiente era colorido. A produção era alegre, até porque tinha sempre, como marca, o acompanhamento de trilha sonora cuidadosamente escolhida pela dona da fábrica, uma italiana radicada no Brasil desde criança, que aprendeu a gostar de samba e música popular. Ela mesma emanava energia potente de produção, de mais e mais florescimentos, porque ali estava inteira, autêntica, vibrante, amorosamente derramada, no traço forte dessa característica nos italianos. (Fragmento de Diário de Pesquisa, Trilha Saberes Pessoais)

${ }^{2}$ A referência aqui é a Jung (1991), que apresenta a intuição no seu texto Tipos Psicológicos, assim como em aulas e textos de Edvaldo Pereira Lima. Este último autor, na proposição do Jornalismo Literário Avançado, reconhece a importância de pressupostos da filosofia oriental e relativos ao mundo sensível, como os inerentes à mitologia. Além de Jung, Edvaldo defende a utilização desses pressupostos para a produção do Jornalismo e do Conhecimento. Vários dos seus textos trazem pistas, nesse sentido. Destaco aqui os livros Colombia, Espelho América, Econautas - Jornalismo e Ecologia, Páginas Ampliadas, Ayrton Senna - Guerreiro de Aquário, Escrita Total. (LIMA, 1987; 1996; 2004; 1998; 1995; 2009). 
Penso que aprendi a ser professora com ela, Rita Cardinale, com essa energia vibrante, de que mobiliza almas, para produzir florescimentos, com arte, com técnica, com os recursos existentes, com prazos a serem vencidos para entregar as encomendas, com suavidade das pétalas, com força da engrenagem maquínica ${ }^{3}$ a ser acionada para cortar, prensar, frisar, fazer os encaixes e arremates, para montar os galhos rizomáticos ${ }^{4}$ de florescimentos, os arranjos organizados delicadamente para comunicar e produzir sensação agradável, pela conexão cuidadosa de entrelaçamentos de flores, florescimentos, resultado de tantos trabalhos. Qualquer semelhança com a vida a acadêmica e o ofício de educadora, florista de processos de florescimentos da Ciência, não é mera coincidência. Pode mais facilmente ser compreendido como sincronicidade ${ }^{5}$ e a acionamento de campos morfogenéticos ${ }^{6}$, universos de energias potentes que fazem possível a produção, a reinvenção de sujeitos, processos, práticas, paradigmas, com potência capaz de superar todo e qualquer tipo de desafio e dificuldade.

Nesse sentido, houve um momento, em que tentava terminar o relatório de qualificação da minha dissertação, em uma das muitas madrugadas em que me dediquei à Ciência, na vida. O texto estava travado. Eu não conseguia terminar, até que um 'pensamento atravessado' - assim o chamei no texto mesmo que escrevia - me fez lembrar outras madrugadas em que me dediquei para terminar encomendas de flores, com minha família, ali, juntos, obstinados por cumprir prazos e fazer bonito, nas nossas produções. Entendi, então, que estava vivendo uma 'dobra', esquizoanaliticamente falando, um desdobramento da mesma cena (ALMEIDA, 2011). Como eu disse no texto, madrugada do pensamento atravessado, eu produzia flores, com a alegria de uma produção compartilhada com pessoas que amava e amo ainda hoje. Não tinha certezas sobre como essas flores seriam recebidas por quem as encontrasse, mais adiante nos percursos de vida. Entendi que o mesmo acontecia,

${ }^{3}$ Engrenagem maquínica é um termo que utilizo, com fundamentação esquizoanalítica, significando referência às grandes engrenagens abstratas, às grandes amarras de produção do sujeito. A máquina, aqui não é apenas a máquina concreta, mas principalmente os maquinismos invisíveis que produzem os sujeitos enredados em engrenagens de modos de vida e de produção de si mesmos. Um texto muito interessante de Guattari (1992), nesse sentido, é intitulado Caosmose Caosmose. Um Novo Paradigma Ético-Estético.

${ }^{4}$ A expressão aqui está sendo utilizada no sentido atribuído por Deleuze e Guattari (1995), especialmente no livro, Mil Platôs n.1. Rizoma é um conceito da botânica, uma espécie de raiz que tem brotação irregular, diferenciada, derivativa, sem possibilidade de previsão rígida. Há uma irregularidade na brotação do rizoma e este é o principal dado de significação aqui.

${ }^{5}$ O termo "sincronicidade" foi proposto por Carl Gustav Jung, para representar coincidências que aconteceriam não por acaso, mas sim com um propósito. O conceito foi cunhado na época de parceria com o físico Wolfgang Pauli e veio a público em livro de autoria dos dois, publicado em 1952. Nesse livro, Pauli escreveu o artigo: "A influência das ideias arquetípicas nas teorias científicas de Kepler", e Jung publicou o texto: "Sincronicidade: um princípio de conexão acausal” (PESSOA JR, 2007-2011).

${ }^{6}$ Teoria criada por Rupert Sheldrake, fisiologista inglês, correspondendo a estruturas invisíveis que se estendem no espaço-tempo e que, segundo Sheldrake, moldam a forma e o comportamento de todos os sistemas do mundo material. 
então, com minhas flores-palavras, produzidas no escuro da madrugada, com carinho, mas sem certezas sobre como seriam recebidas. Animava-me, nos dois processos, a confiança no devir, a esperança, a confiança nas parcerias de trabalho, a amorosidade que transversalizava e que empurrava a fazer mais e mais... pensando... vamos... faz com carinho, faz tua parte... e depois, entrega, se entrega. O risco, o salto, o gozo, a alegria está na produção mesma e no vislumbre o olhar, do toque nos afetos, no arrepio na pele, do encantamento pela possibilidade de encontro de floresceres, flores, palavras, seres, sentimentos, dizeres, tudo junto, entrelaçados em corpos intensidades, que interagem nas produções que vale a pena.

O encontro com a floresta. Outra inspiração para o pressuposto epistemológico-teórico trama de floresceres, como já me referi, é o meu encontro com a floresta Amazônica. Vivi alguns anos, desde 1990 a 2010, buscando aprimorar processos de ensino de pesquisa e, entre as estratégias mentais que desenvolvi, estava a de comparar o processo de produção de pesquisa com uma viagem, mais especificamente com uma viagem na floresta. Assim, em 2010, fui convidada pelo Professor Doutor Gilson Vieira Monteiro, na época coordenador do Programa de Pós-Graduação em Ciências da Comunicação da Universidade Federal do Amazonas, para falar sobre o conceito de paixão-pesquisa e sobre a visão de metodologia mais aberta, sensível, que eu já vinha propondo. Era um momento mágico, para mim. $\mathrm{Na}$ mesma viagem, encontrei com o professor e hoje grande amigo Jorge Gonzalez, do México, que também dava um curso sobre Metodologia da Pesquisa - ele já era um expoente internacional sobre o assunto. Eu, sua admiradora, confessa. Então, naquele dia, quando vi o auditório se enchendo para a minha palestra, pensei: "Meu Deus, mas que arrogância, como eu posso falar para essas pessoas que fazer pesquisa é fazer uma viagem pela floresta, se eu nunca tinha chegado perto da floresta". Naquele momento, então, resolvi descer do palco e ir até a floresta pedir licença para falar, pedir permissão. Tempos depois, outro professor e amigo, Wilson Nogueira, me disse que eu fiz o que os índios recomendam, como celebração e respeito, para entrar na floresta. É preciso pedir licença, respeitosamente aos seres da floresta. Foi o que fiz. Ao final da minha fala, no exato momento em que as pessoas aplaudiam, começou a chover, mas uma chuva torrencial, amazônica. O Professor Gilson se aproximou de mim e disse que a chuva era a forma da floresta dizer que queria fazer germinar as sementes da 'paixão-pesquisa' - meu conceito - que eu tinha levado para lá. Emocionada, eu chorei, chovi.

Em outro momento, enquanto trabalhava na sala do Pró-Reitor de Pesquisa e PósGraduação da UFAM, levantei os olhos e me impactei com a imagem. Fiquei um tempo ali pensando, sentindo, refletindo e, eu mesma, embrenhada na trama da floresta, trama de 
floresceres. Comecei, naquele momento, a responder a uma pergunta que eu vinha me fazendo sobre o que me ligava tão fortemente à floresta, de onde havia tanta intensidade no meu vínculo, na minha relação com a floresta, eu que sempre tive medo de bichos, medo de tantas coisas... por que a floresta me encantou tanto e porque eu a sentia parte de mim mesma? A foto me deu as respostas.

Figura 1 - Trama da floresta amazônica

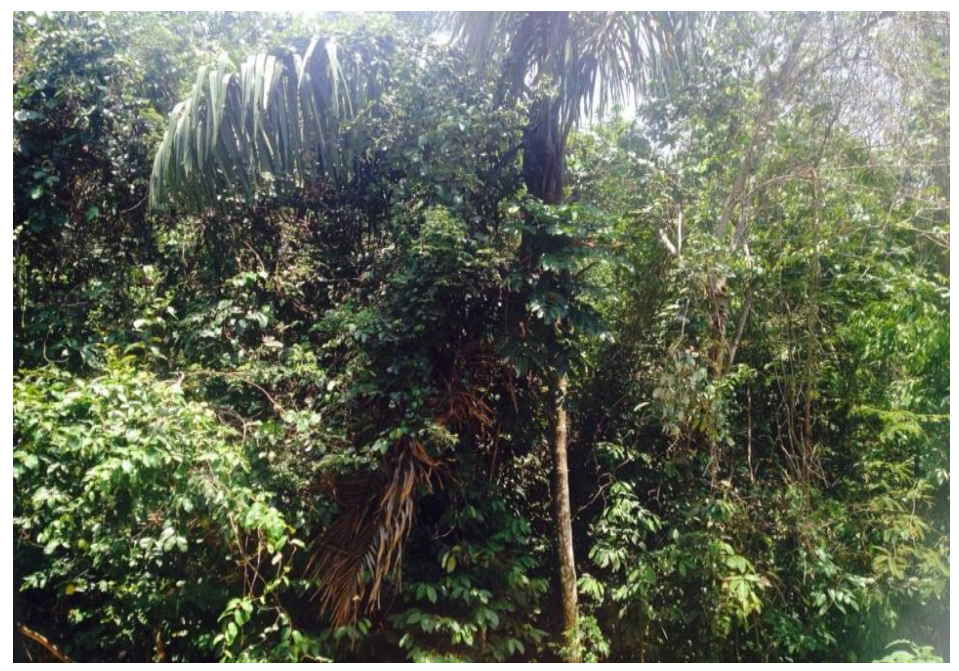

Fonte: Da autora.

A trama dos floresceres encanta porque a força está nos entrelaçamentos. O mesmo acontece no ensino, na Ciência, na vida. Relembro aqui, outro texto que escrevi e apresentei no Seminário Nacional da Pós-Graduação em Turismo, da ANPTUR, em 2019, intitulado “Amar la trama más que el desenlace!”. Reflexões sobre as proposições Trama Ecossistêmica da Ciência, Cartografia dos Saberes e Matrizes Rizomáticas, na Pesquisa em Turismo (BAPTISTA, 2019).

\section{Trama dos floresceres - Saberes Teóricos}

A imagem da floresta é sinalizadora para a constituição da trama epistemológicoteórica dos meus estudos. A síntese dos pressupostos está na palavra 'trama', mais especialmente na combinação 'trama de floresceres'. Então, vamos aos poucos. Trama expressa entrelaçamento, trançados, enredamento de fios, fluxos, phyluns que se juntam e de amaram combinando um nó ou vários. Essa ideia me remete imediatamente ao pensamento de Ylia Prigogine (2001), quando explica suas estruturas dissipativas, ajudando a compreender 
que a própria trama não é fixa, mas processual, porque dela derivam fios que se escapam, abrindo novas possibilidades.

Trama é também a teia da vida, no que se compreende facilmente a conexão com o pensamento sistêmico, cuja trajetória e pressupostos estão bem apresentados por Fritjof Capra (1997), no livro A Teia da Vida. Trata-se, então, aqui de uma teia da vida ecossistêmica, trabalhando com pressupostos da Ecologia Profunda de Arne Naess, também apresentados por Capra, pressupostos esses que extrapolam a relação entre fatores bióticos e abióticos, para a composição de uma trama caosmótica - de caos, osmose, no cosmo - de elementos visíveis e invisíveis, campos de energias intensas também, em que a noção holo se verifica, tudo e todos compõem a trama-teia viva pulsante, mutante, máquina autopoiética a ser cuidada e agenciada constantemente nos processos educacionais. A noção de caosmose tem fundamentação aqui em Felix Guattari (1992), no livro Caosmose. Um Novo Paradigma Ético-Estético e Edgar Morin (2013), em Ciência com Consciência. A visão holo remete, ainda, ao texto de Roberto Crema (1989), Introdução à Visão Holística.

Trama são as pessoas que se juntam em entrelaços de amorosidade, em processos pautados pela noção de Amor, de Humberto Maturana (1998), quando este ensina que o Amor é o reconhecimento do outro como legítimo outro na convivência. No Amorcomtur!, temos trabalhado esse conceito como uma espécie de mantra, abrindo-o para entender que o 'outro é outro', não sou eu; é diferente, é outro universo existencial - e aqui já estou associando a visão esquizoanalítica dos universos existências de referências, também trabalhados por Guattari, no livro Caosmose. Bem, o outro sendo outro, é legítimo outro, o que remete imediatamente a compreender que ele tem direito de ser outro, o que lhe confere legitimidade para ser assim, diferente, diverso, composto por outros feixes de significação e constituição de seu universo. Respeitando-o, nas suas diferenças, eu invisto na convivência, o que conclui o conceito, quando o autor complementa, afirmando que esse reconhecimento do outro como legítimo outro é algo que ocorre 'na convivência'.

Então, o grande investimento passa a ser conviver com as diferenças e entrelaçarmonos, respeitosamente, em teia da vida, para fazer dessas nossas diferenças laços complementares e acionadores de potência de mais vida e de outros liames, outros devires laços, que nos conectem com outros seres e assim possamos seguir fazendo fluir afetos, sentimentos, saberes. Isso se faz no cotidiano da Educação Amorcomtur, nas suas diversas manifestações, em rodas de conversas, os nossos Encontros Caóticos, nas aulas, nos corredores, nos eventos, nos textos produzidos. Assim, sujeitos teia-trama-amorosos se entrelaçam com outros sujeitos, o que potencializa a trama de floresceres na Educação. 
Trama são também os momentos e processos da Educação. É preciso compreender aqui que os pressupostos de processualidade e complexidade constituem o movimento da trama de floresceres. A trama é puro movimento, fluxo constante de enredamentos, como os phyluns e galhos de uma floresta, que vão também se enredando e acoplando, em fluxos de geração de nova vida. Nesse processo, cada momento e sujeito precisa ser cuidado, em sua potência de nó de convergência e nó de passagem, para lembrar Prigogine. Fluxos que convergem, que se encontram e sinalizam devires de novos fluxos, novas passagens, novos encontros. Isso significa que o que se produz na Educação não se faz em sala de aula, apenas, mas no processo derivativo, dissipativo decorrente do que ocorre ali e em tantos outros momentos. O que se produz na Educação não se circunscreve nos espaços de sala de aula ou mesmo das escolas ou universidades. O que se produz na Educação se espraia rizomaticamente pelo ecossistema todo, alterando o mundo da vida da maioria das pessoas. Por isso, especialmente, precisa ser tão cuidado e valorizado. O mundo da Educação aciona potência de transformação coletiva, envolvendo sujeitos e todos os seres e elementos do ecossistema, desde as suas grandiosas manifestações até as mais ínfimas presenças em fluxos, substâncias e energias.

As tramas bem tramadas geram novas vidas, geram novas brotações e combinações, geram o florescimento de novas florações, e aqui a redundância é proposital.

\section{De que ensino e de que ciência estou falando?}

Houve um momento, na minha vida, em que dei supervisão para o texto da dissertação de mestrado de Lígia Hecker Ferreira (1998), que estudava o que ela chamou de O Mal-Estar na Escola. Eu, então, a provoquei para procurar a etimologia da palavra escola, porque, por natureza e ofício, tenho apreço pelas palavras e penso que elas são como caixas de enigmas de significação. À medida decidimos abrir essas caixas encontramos preciosidades e marcas do passado, que nos ajudam a compreender o mundo e a presença desta palavra entre nós, até hoje. Enfim, ao buscar, ela encontrou 'no fundo etimológico da palavra escola' a ideia de repouso. Educação, escola, repouso, o enfrentamento com o mal estar.... nós passamos muito tempo discutindo a relação entre esses sentidos. Eu propus pensar que a escola é um lugar de 're-pouso', para onde se vai para pousar, descansar das turbulências da vida, para depois desse pouso, levantar outros voos. Claro, eu entendia ali as marcas de um processo coletivo de transformação da Educação, que durante um tempo foi marcada pelo encastelamento dos processos educacionais, responsabilidade de tutores, cuja atividade era desenvolvida nas 
próprias residências, de quem podia se dar ao luxo do acesso ao conhecimento. Assim, a desterritorialização do universo de aprendizagem decorreu de todo um processo de transformações socioeconômicas e políticas, com o deslocamento para um 'lugar' de repouso e lazer, a 'escola'.

$\mathrm{Na}$ trilha da etimologia, é interessante observar a relação entre repouso, descanso e lazer, vinculada à escola, o que, na lógica capitalística contemporânea, destoa em grande parte do que crianças e jovens parecem sentir e pensar em relação à escola.

Observa-se no latim como schola, sobre o grego scholé, para entender a ideia de lazer, recreação ou tempo livre, pois, desde suas origens, para os gregos, a aprendizagem esteve relacionada à ideia de entretenimento e interesse individual, distanciando-se das obrigações e do trabalho (ETMOLOGIA, 2020, grifo nosso).

A palavra "escola" tem sua origem na Grécia antiga, com SKHOLE, que foi evoluindo até o Latim SCHOLA. Os termos de ambas as línguas tem o mesmo significado, "discussão ou conferência", mas também significavam "folga, ócio". Este último significado, no caso, seria um tempo ocioso onde era possível ter uma conversa interessante e educativa (GRAMATICA.NET, 2020, grifo do autor).

Igualmente curiosa é a etimologia de Educação. Vamos observar, a partir de duas fontes:

A palavra "Educação", em português, vem de "Educar", a origem desta, por sua vez, é do Latim EDUCARE que é uma derivado de EX, que significa "fora" ou "exterior" e DUCERE, que tem o significado de "guiar", "instruir", "conduzir". Ou seja, em latim, educação tinha o significado literal de "guiar para fora" e pode ser entendido que se conduzia tanto para o mundo exterior quanto para fora de si mesmo (GRAMATICA.NET, 2020, grifo do autor).

Educação é a forma nominalizada do verbo educar. Aproveitando a contribuição de Romanelli (1960), diremos que educação veio do verbo latim educare. Nele, temos o prevérbio e- e o verbo - ducare,- dúcere. No itálico, donde proveio o latim, dúcere se prende à raiz indo-européia DUK-, grau zero da raiz DEUK,cuja acepção primitiva era levar, conduzir, guiar. Educare, no latim, era um verbo que tinha o sentido de "criar (uma criança), nutrir, fazer crescer. Etimologicamente, poderíamos afirmar que educação, do verbo educar, significa "trazer à luz a idéia" ou filosoficamente fazer a criança passar da potência ao ato, da virtualidade à realidade. Possivelmente, este vocábulo deu entrada na língua no século XVII (MARTINS, 2005, p. 32, grifo nosso).

Eu gosto de pensar em guiar para fora e fazer passar da potência ao ato, desde que se compreenda que Educação se faz na trama, no entrelaçamento de sujeitos e resulta desse 
entrelaçamento e das relações de confiança e alegria, que se estabelecem nos processos de ensino-aprendizagem.

Ao mesmo tempo, ressalto que a Ciência de que falo, aqui, neste texto, é aquela que faz as pazes com o saber comum, com as dimensões de sabedoria comum, não encastelada. Aqui, há a referência direta aos ensinamentos de Boaventura de Sousa Santos, em vários textos, mas destaco a fala em Um Discurso sobre as Ciências na transição para uma ciência pós-moderna. "A ciência pós-moderna, ao sensocomunizar-se, não despreza o conhecimento que produz tecnologia, mas entende que, tal como o conhecimento, se deve traduzir em autoconhecimento, o desenvolvimento tecnológico deve traduzir-se em sabedoria de vida" (SANTOS, 1988, p. 70).

Trata-se da Ciência em teia da vida também, na recombinação das grandes engrenagens e no reconhecimento das potências das máquinas autopoiéticas de produção de subjetividade e de saberes, máquinas subjetivas e técnicas acionadas para compreender o mundo, no engendramento de dimensões a-significantes incorporais, pelas intensidades abstratas dos processos desejantes e de afetivações (de ações que mobilizam os afetos) dos sujeitos (GUATTARI, 1992; GUATTARI; DELEUZE, 1995). Os resultados das produções científicas podem ser números, processos, substâncias ou equipamentos, mas o que me parece relevante é que esses processos correspondam à autopoiese dos sujeitos e instituições que promovem a Ciência, o seu ensino e produção, sempre em sintonia com valores que gerem o bem comum. Isso considerando que suas ações têm a característica derivativa, dissipativa e rizomática, no sentido de se derramar brotações, florações, na sociedade, no ecossistema todo, gerando transformação, transmutação, que, esperamos seja responsável ecossistemicamente, voltada ao bem comum. Assim, a noção de Ciência, aqui, tem caráter enativo e inscriacional. O caráter enativo remete ao pensamento de Francisco Varela (1992), quando este propõe o conceito de enação, para se referir ao conhecimento. A palavra inscriacional foi cunhada na minha tese, já relacionada ao processo de escrita da Ciência, como um processo em que o sujeito se inscreve, cria e aciona devires, outros mundos inscritos e em potência entrelaçada de vida, outros floresceres (BAPTISTA, 2000).

\section{Trama de Saberes - Usina de Produção Percursos Amorcomtur!}

Para seguir refletindo sobre a Trama de Floresceres no Ensino da Ciência, resgato, agora, um pouco do percurso do Amorcomtur! Grupo de Estudos em Comunicação, Turismo, Amorosidade e Autopoiese. Na verdade, em coerência com o referencial teórico, percebo que 
o percurso do Amorcomtur é rizomático, o que faz que sejam, na verdade, percursos derivativos e dissipativos de brotações. O grupo surgiu em 2011, na Universidade de Caxias do Sul, pautado por duas grandes orientações, com os pressupostos conceituais que lhe dão nome: amorosidade e autopoiese. Amorosidade como ética da relação, ética do cuidado, como laço intenso de afeto e respeito que nos une e que, acreditamos, como Maturana (1998), constitui a base do laço social. Autopoiese como autoprodução, transposta para a ideia de reinvenção de si mesmo, em entrelaçamento com outros integrantes do sistema. $\mathrm{O}$ conceito de Maturana parte de seus estudos desde a Biologia, em que se refere à autopoiese desde os processos celulares. Entendo, no entanto, ser pertinente pensar a autopoiese para sistemas complexos amplos, como a Educação, a Comunicação, a Política, o Turismo, alguns dos quais abordados pelo próprio Maturana. Destaco, em especial, o fato de que o processo de autopoiese só é desencadeado se a célula estiver no sistema, em meio à rede de ações recorrentes de cooperação dos fluxos internos ao sistema. Isso me parece interessante para pensar a Educação e, também, para compreender o caráter autopoiético do Amorcomtur. A constatação é quase óbvia: o processo de autopoiese e reinvenção só é possível quando os integrantes então 'juntos', no sistema, em interações recorrentes, pulsando vida.

Nesse sentido, percebo que nos percursos realizados até agora, as marcas de amorosidade, confiança e alegria têm sido constantes e sinalizadoras de potência, em processos autopoiéticos de ensino e produção da Ciência. O Amorcomtur tem se constituído como um campo de potências acionadas, em que a confiança e a alegria transversalizam nossas ações, nossas relações, os acontecimentos vários, contribuindo para o agenciamento de potencialidades singulares e a ampliação e mobilização desejante de arregimentar mais e mais pesquisadores amorosos, para a produção alegre na trama de floresceres científicos Amorcomtur.

Bem, dos percursos, há o do próprio grupo, como coletivo, que surge em 2011. No mesmo ano, já foi chamado para integrar a Rede Nacional de Grupos de Pesquisa em Comunicação, organizada pelo Professor Doutor Ciro Marcondes Filho, como um grupo diferencial, para discutir ontologia, epistemologia e metodologia, do que esse autor já vinha chamando de Nova Teoria da Comunicação. Em 2013, com a associação do percurso do grupo ao Programa de Pós-Graduação em Turismo e Hospitalidade, da Universidade de Caxias do Sul, houve a mudança do Amorcom! (nome original) para o Amorcomtur!, sinalizando a interface entre os dois campos de conhecimento. De iniciativa isolada da pesquisadora líder, com alguns poucos alunos, o grupo passou a produzir entrelaços, vínculos 
com pesquisadores, tanto na própria universidade, mas também com outras universidades brasileiras.

Depois de participar em vários eventos nacionais, já com viagens interestaduais, em 2014, tivemos a primeira participação de integrantes da graduação, em eventos internacionais, o que aconteceu no II Congresso Mundial de Comunicação Ibero-americana, que aconteceu em Braga, Portugal, e no XI Lusocom, que ocorreu na Universidade de Vigo (Campus de Pontevedra) Galicia - España. Na época, dois integrantes do Amorcomtur, estudantes de Jornalismo, Jennifer Bauer Eme e Ronaldo Velho Bueno, apresentaram trabalhos. Eram os únicos alunos de graduação nos dois eventos.

Um momento marcante também foi a aprovação do projeto AMORCOMTUR! Usina de Saberes Luso-Brasileiros. Com-versar viagens investigativas interculturais, a partir do acionamento de amorosidade e autopoiese, nas rodas de conversa, como dispositivo de afetivação para a pesquisa - UCS-UFAM-UFRN/UC, em edital UCS - Santander, que possibilitou uma nova viagem para a Europa, desta vez para a integração com a Universidade de Coimbra. Na ocasião, interagimos com vários pesquisadores da área de Turismo, como os professores Doutor João Luis Jesus Fernandes, investigador do Centro de Estudos de Geografia e Ordenamento do Territórios (CEGOT), Norberto Pinto dos Santos, Professor Associado com Agregação no Departamento de Geografia da Faculdade de Letras da Universidade de Coimbra e Investigador no Centro de Estudos de Geografia e Ordenamento do Território. Coordenador do Mestrado em Turismo. Um destaque especial para o encontro com Boaventura de Sousa Santos, Professor Catedrático e Diretor do Centro de Estudos Sociais da Universidade de Coimbra e Diretor do Centro de Documentação 25 de Abril da mesma Universidade.

Destaco, ainda, com a Universidade Federal do Amazonas, iniciado em 2015. o Projeto, em nível de pós-doutoramento, no Programa de Pós-Graduação em Sociedade e Cultura da Amazônia, intitulado Entrelaços Caosmóticos com Saberes Amazônicos: Percorrendo as Trilhas Inscriacionais da 'Ciência em Movimento', na Sociedade e Cultura da Amazônia.

Na Universidade de Caxias do Sul, os outros projetos desenvolvidos: TRAMA AMORCOMTUR! Complexos processos comunicacionais e subjetivos, que potencializam o turismo, considerados sobre o viés da amorosidade e autopoiese (2016-2018); ECOSSISTEMAS TURÍSTICO-COMUNICACIONAIS-SUBJETIVOS: Sinalizadores teórico-metodológicos, no estudo de ecossistemas turístico-comunicacionais-subjetivos, considerados a partir de sua característica ecossistêmica, caosmótica e autopoiética (2018- 
atual); e 'Com-versar' Amorcomtur - Lugares e Sujeitos! Narrativas transversais sensíveis, envolvendo sujeitos em processos de desterritorialização - Brasil, Espanha, Portugal, Itália, México, Colômbia, Egito, Arábia Saudita e Índia.

Com os pós-graduandos, pesquisadores Amorcomtur, as produções da Ciência floresceram com as seguintes abordagens, que, por sua vez brotaram em vários artigos para publicação em periódicos e apresentação em eventos nacionais e internacionais. Destaco aqui as produções matrizes, das quais floresceram tantas outras:

\section{Quadro 1 - Produções Matrizes}

\begin{tabular}{|c|c|c|c|}
\hline Autor & Título & Tipo & Ano \\
\hline Renan de Lima da Silva & $\begin{array}{l}\text { Em ondas com o turismo: o olhar da comunidade sobre o } \\
\text { turismo nas praias do farol de Santa Marta. }\end{array}$ & Dissertação & 2015 \\
\hline $\begin{array}{l}\text { Charlene } \\
\text { Puerto }\end{array}$ & $\begin{array}{l}\text { Turismo em cemitérios. um estudo sobre o cemitério como } \\
\text { patrimônio e atrativo turístico, considerando a ambivalência } \\
\text { morte e vida das necrópoles. }\end{array}$ & Dissertação & 2016 \\
\hline Carlos Leoni & $\begin{array}{l}\text { Jammo in Cantina? C que sabe! a italianidade na gastronomia } \\
\text { paulistana: marcas de hospitalidade e amorosidade. }\end{array}$ & Dissertação & 2017 \\
\hline Renato Dos Santos Lima & $\begin{array}{l}\text { Turismo, hospitalidade e amorosidade: os sujeitos-devotos do } \\
\text { círio de nossa senhora de nazaré em belém do Pará. }\end{array}$ & Dissertação & 2017 \\
\hline Natalia Biazus & $\begin{array}{l}\text { Turismo, comunicação e a perspectiva trama. sinalizadores- } \\
\text { síntese do festival brasileiro de música de rua e suas relações } \\
\text { com o turismo em Caxias do Sul. }\end{array}$ & Dissertação & 2017 \\
\hline $\begin{array}{l}\text { Newton Fernandes de } \\
\text { Ávila }\end{array}$ & Dança circular: um corpo que se expressa e acolhe & Dissertação & 2017 \\
\hline Adriano Silva Rodrigues & $\begin{array}{l}\text { Aturá: trançado de saberes amazônicos. estudo de caso da } \\
\text { rádio Tribos do Norte. }\end{array}$ & Dissertação & 2017 \\
\hline Vanilson Pereira Silveira & $\begin{array}{l}\text { Garibaldi: destino cinematográfico! um estudo sobre a relação } \\
\text { entre cinema e turismo no município de Garibaldi/RS. }\end{array}$ & Dissertação & 2018 \\
\hline Camila Carvalho de Melo & $\begin{array}{l}\text { Caminhada noturna do turismo tramas subjetivas e } \\
\text { comunicacionais no processo de desterritorialização. }\end{array}$ & Dissertação & 2018 \\
\hline Mara Regina Thomazi & $\begin{array}{l}\text { Hostel: território de hospedagem marcado pela trama turístico- } \\
\text { comunicacional. }\end{array}$ & Dissertação & 2019 \\
\hline Helena Charko Ribeiro & $\begin{array}{l}\text { Turismo e saúde. sinalizadores turísticos de Porto Alegre, } \\
\text { relatados pelos usuários do Sistema Único de Saúde (Sus) seus } \\
\text { acompanhantes, em processos de deslocamento. }\end{array}$ & Doutorado & 2019 \\
\hline
\end{tabular}

Fonte: elaborado pela autora.

\section{Considerações finais}

A abordagem aqui intitulada “Trama de 'Floresceres' no Ensino da Ciência. Percursos orientados por entrelaços de amorosidade, confiança e alegria, em processos autopoiéticos de ensino e produção da Ciência" correspondeu a uma narrativa científica, em coerência às Trilhas da Cartografia dos Saberes: Saberes Pessoais, Saberes Teóricos, Usina de Produção e Dimensão Intuitiva da Pesquisa. Esta última está transversalizada, com aproximações e ações que perpassam a trama, a partir da disposição de escuta sensível a todos os fatores intervenientes. Nesse modo de produzir Ciência, sincronicidades são sempre 'escutadas' 
como sinalizadores. Cada uma das produções apresentadas na Usina de Produção teve sua rota direcionada, também por pistas que se insinuaram e expressões sutis ou eventos inesperados no percurso.

Talvez possamos pensar que o trabalho de Camila Carvalho de Melo seja emblemático, nesse sentido, quando aborda a Trilha Noturna de Criúva, por ter nos ajudado a refletir tanto para o fato de que a produção da Ciência, no Amorcomtur, parte do pressuposto, sim de uma viagem na floresta, mas reconhece o caráter noturno dessa viagem. O pesquisador caminha segurando uma 'corda'. Ele, então, 'acorda' para um percurso que vai se fazendo a cada passo, em um caminho construído pelas suas experiências e saberes anteriores, que o levaram até ali, pelos seus saberes teóricos, que o orientam no percurso, e pela experiência mesma, do percurso, que vai dizendo como seguir adiante. Nesse processo, confiança (o que garante, fia, a andança), alegria (como potência de agir) e amorosidade (como reconhecimento de si mesmo e do outro, como legítimos, na convivência) são fatores fundamentais, para que o pesquisador se sinta motivado ao próximo passo, e depois ao próximo e ao outro. Arriscar-se a seguir adiante, sem certezas, mas com a intuição de um devir clarão, de que em algum momento, o percurso vai fazer sentido, assim como vai fazer sentido o medo, o estremecimento, a emoção, a dúvida, os questionamentos todos, inclusive (e talvez principalmente) os existenciais.

\section{REFERÊNCIAS}

ALMEIDA, Lutero Pröscholdt. Dobras de Deleuze, Desdobramentos de Lina Bo Bardi. As Dobras Deleuzianas nos Desdobramentos ético-estéticos de Lina Bo Bardi. Orientador: Prof. Dr. Fernando Gigante Ferraz. 2011. 138 f. Dissertação (Mestrado em Arquitetura e Urbanismo) - Faculdade de Arquitetura e Urbanismo, Universidade Federal da Bahia. Salvador, 2011.

ÁVILA, Newton Fernandes de. Dança Circular: um corpo que se expressa e acolhe. 2017. 120 f. Dissertação (Mestrado em Turismo) - Programa de Pós-Graduação em Turismo e Hospitalidade, Universidade de Caxias do Sul, Caxias do Sul, 2017.

BAPTISTA, M. L. C. 'Amar la trama más que el desenlace!'. Reflexões sobre as proposições trama ecossistêmica da ciência, cartografia dos saberes e matrizes rizomáticas, na pesquisa em turismo. In: SEMINÁRIO ANUAL DA ASSOCIAÇÃO NACIONAL DE PESQUISA E PÓS-GRADUAÇÃO EM TURISMO, 16., 2019. Curitiba. Anais[...] Curitiba, 2019. p. 1.

BAPTISTA, Maria Luiza Cardinale. Ecossistemas turístico-comunicacionais-subjetivos: Sinalizadores teórico-metodológicos, no estudo de ecossistemas turísticocomunicacionaissubjetivos, considerados a partir de sua característica ecossistêmica, caosmótica e autopoiética. Projeto de pesquisa. Núcleo de Pesquisa Turismo: Desenvolvimento Humano e 
Social, Linguagem e Processos Educacionais (SOCIOEDUC). Universidade de Caxias do Sul, 2018.

BAPTISTA, Maria Luiza Cardinale. O sujeito da escrita e a trama comunicacional. Um estudo sobre os processos de escrita do jovem adulto como expressão da trama comunicacional e da subjetividade contemporânea. Orientador: Mauro Wilton de Sousa. 2000. 440. f. Tese (Doutorado em Ciências da Comunicação) - Escola de Comunicações e Artes, Universidade de São Paulo, 2000.

BAPTISTA, Maria Luiza Cardinale. Trama AMORCOMTUR! Complexos processos comunicacionais e subjetivos, que potencializam o turismo, considerados sobre o viés da amorosidade e autopoiese. Projeto de pesquisa. Núcleo de Pesquisa Turismo:

Desenvolvimento Humano e Social, Linguagem e Processos Educacionais (SOCIOEDUC). Universidade de Caxias do Sul, 2016-2018.

BIAZUS, Natalia. Turismo, Comunicação e a Perspectiva Trama. sinalizadores-síntese do festival brasileiro de música de rua e suas relações com o turismo em Caxias do Sul. 2017. Dissertação (Mestrado em Turismo) - Programa de Pós-Graduação em Turismo e Hospitalidade, Universidade de Caxias do Sul, Caxias do Sul, 2017.

CAPRA, Fritjof. A teia da vida. Uma nova compreensão dos sistemas vivos. 9. ed. São Paulo: Cultrix, 1997.

CREMA, Roberto. Introdução à visão holística. Breve relato de viagem do velho ao novo paradigma. São Paulo: Summus, 1989.

DELEUZE, Gilles; GUATTARI, Félix. Mil platôs. Capitalismo e esquizofrenia. Rio de janeiro: 34. ed. 1995.

FERREIRA, Lígia Hecker. O mal-estar na escola. Uma pragmática ético-estética. Orientadora: Suely Belinha Rolnik. 1998. 143 f. Dissertação (Mestrado em Psicologia Clínica) - Pontifícia Universidade Católica de São Paulo, São Paulo, 1998.

ETMOLOGIA. Etmologia de escola. Origem do significado. Disponível em: https://etimologia.com.br/escola/. Acesso em: 30 mar. 2020.

GRAMATICA.NET. Etimologia de "escola". Origem das palavras. Disponível em: https://www.gramatica.net.br/origem-das-palavras/etimologia-de-escola/_. Acesso em: 30 mar. 2020.

GRAMATICA.NET. Etimologia de "educação". Origem das palavras. Disponível em: https://www.gramatica.net.br/origem-das-palavras/etimologia-de-educacao/. Acesso em: 30 mar. 2020.

GUATTARI, Felix. Caosmose. Um novo paradigma ético-estético. 34. ed. Rio de Janeiro, 1992.

JUNG, Carl Gustav. Tipos psicológicos. 7. ed. Petrópolis: Editora Vozes, 1991. 
LEONI, Carlos. Jammo in Cantina? C Que Sabe! A italianidade na gastronomia paulistana: marcas de hospitalidade e amorosidade. Orientadora: Maria Luiza Cardinale Baptista. 2017. 104 f. Dissertação (Mestrado em Turismo) - Programa de Pós-Graduação em Turismo e Hospitalidade, Universidade de Caxias do Sul, Caxias do Sul, 2017.

LIMA, Edvaldo Pereira (Coord.). Econautas: ecologia e jornalismo literário avançado. Canoas, RS: Universidade Luterana do Brasil, 1996. (Coleção Mundo Mídia).

LIMA, Edvaldo Pereira. Ayrton Senna. Guerreiro de aquário. São Paulo: Editora: Brasiliense, 1995.

LIMA, Edvaldo Pereira. Colômbia Espelho América: dos piratas a Garcia Márquez, viagem pelo sonho de integração latino-americana. São Paulo: Perspectiva/EdUSP, 1987.

LIMA, Edvaldo Pereira. Da escrita total à consciência planetária. In: Brandão, CARLOS Henrique; ALESSANDRINI, Cristina. (Orgs.). Criatividade e novas metodologias. São Paulo: Petrópolis, 1998.

LIMA, Edvaldo Pereira. Escrita total. Escrevendo bem e vivendo com prazer, alma e propósito. São Paulo, Sistema Clube de Autores, 2009.

LIMA, Edvaldo Pereira. Páginas ampliadas: o livro-reportagem como extensão do jornalismo e da literatura. São Paulo: Manole, 2004.

LIMA, Renato dos Santos. Turismo, hospitalidade e amorosidade: os sujeitos-devotos do círio de nossa senhora de nazaré em Belém do Pará. Orientadora: Maria Luiza Cardinale Baptista. 2017. 196 f. Dissertação (Mestrado em Turismo) - Programa de Pós-Graduação em Turismo e Hospitalidade, Universidade de Caxias do Sul, Caxias do Sul, 2017.

MARTINS, Evandro Silva. A Etimologia de alguns vocábulos referentes à educação. Olhares \& Trilhas, Uberlândia, Ano. VI, n. 6, p. 31-36, 2005.

MATURANA, Humberto. Emoções e linguagem na educação e na política. Belo Horizonte: UFMG, 1998.

MELO, Camila Carvalho de. Caminhada noturna do turismo tramas subjetivas e comunicacionais no processo de desterritorialização. Orientadora: Maria Luiza Cardinale Baptista. 2018. 99 f. Dissertação (Mestrado em Turismo) - Programa de Pós-Graduação em Turismo e Hospitalidade, Universidade de Caxias do Sul, Caxias do Sul, 2018.

MORIN, Edgar. Ciência com consciência. 15. ed. Rio de Janeiro: Bertrand Brasil, 2013.

PESSOA JR, Osvaldo. Física quântica. Entenda as diversas interpretações da física quântica, 2007-2011. Disponível em: http://opessoa.fflch.usp.br/sites/opessoa.fflch.usp.br/files/VyaQuantica-Tudo.pdf. Acesso em: 30 mar. 2020.

PRIGOGINE, Ylia. Ciência razão e paixão. In: CARVALHO, Edgard de Assis; ALMEIDA, Maria da Conceição de. (Orgs). Tradução: Edgard de Assis Carvalho; Isa Hetzel. Belém, Pará: Eduepa, 2001. 
PUERTO, Charlene Brum Del. Turismo em cemitérios. Um estudo sobre o cemitério como patrimônio e atrativo turístico, considerando a ambivalência morte e vida das necrópoles. 2016. 155 f. Dissertação (Mestrado em Turismo). Programa de Pós-Graduação em Turismo e Hospitalidade - Universidade de Caxias do Sul, Caxias do Sul, 2016.

RIBEIRO, Helena Charko. Turismo e saúde: sinalizadores turísticos de porto alegre, relatados pelos usuários do sistema único de saúde (SUS) e seus acompanhantes, em processos de deslocamento. 2019. 221. f. Tese (Doutorado em Turismo e Hospitalidade) Pró-Reitoria de Pesquisa e Pós-Graduação, Programa de Pós-Graduação em Turismo e Hospitalidade, Universidade de Caxias do Sul, Caxias do Sul, 2019.

RODRIGUES, Adriano Silva. Aturá: trançado de saberes amazônicos. Estudo de caso da rádio Tribos do Norte. Orientadora: Maria Luiza Cardinale Baptista. 2017. 120 f. Dissertação (Mestrado em Ciências da Comunicação) - Programa de Pós-Graduação em Ciências da Comunicação, Universidade Federal do Amazonas, Manaus, 2017.

ROLNIK, Suely. Cartografia sentimental. São Paulo: Liberdade, 1989.

SANTOS, Boaventura de Sousa. Um discurso sobre as ciências na transição para uma ciência pós-moderna. Revista do Instituto de Estudos Avançados da USP, v. 2, n. 2, p. 46-71, 1988.

SILVA, Renan de Lima da. Em ondas com o turismo: O Olhar da comunidade sobre o turismo nas praias do farol de Santa Marta. 2015. 116 f. Dissertação (Mestrado em Turismo). Programa de Pós-Graduação em Turismo e Hospitalidade - Universidade de Caxias do Sul, Caxias do Sul, 2015.

SILVEIRA, Vanilson Pereira. Garibaldi: Destino cinematográfico! Um estudo sobre a relação entre cinema e turismo no município de Garibaldi/RS. Orientadora: Maria Luiza Cardinale Baptista. 2018. 181 f. Dissertação (Mestrado em Turismo) - Programa de PósGraduação em Turismo e Hospitalidade, Universidade de Caxias do Sul, Caxias do Sul, 2018.

THOMAZI, Mara Regina. Hostel: Território de hospedagem marcado pela trama turísticocomunicacional. 2019. 197 fls. Dissertação (Mestrado em Turismo) - Programa de PósGraduação em Turismo e Hospitalidade, Universidade de Caxias do Sul, Caxias do Sul, 2019.

VARELA, Francisco Javier; THOMPSON, Evan; ROSCH, Eleanor. De cuerpo presente. Las ciencias cognitivas y la experiencia humana. Barcelona/Espanha: Gedisa, 1992. 


\section{Como referenciar este artigo}

BAPTISTA, Maria Luiza Cardinale. Trama de 'Floresceres' no ensino da ciência. Percursos orientados por entrelaços de amorosidade, confiança e alegria, em processos autopoiéticos de ensino e produção da ciência. Revista Ibero-Americana de Estudos em Educação, Araraquara, v. 15, n. 3, p. 1322-1342, jul./set., 2020. e-ISSN: 1982-5587. DOI: https://doi.org/10.21723/riaee.v15i3.13623

Submetido em: 19/12/2019

Aprovado em: 02/02/2020

Publicado em: 20/02/2020 